Check for updates

Cite this: RSC Adv., 2019, 9, 21215

\title{
Synthesis of graphene quantum dot-stabilized gold nanoparticles and their application $\uparrow$
}

\author{
Weifeng Chen, ${ }^{\text {ab }}$ Jialu Shen, ${ }^{\text {ab }}$ Shaona Chen, ${ }^{\text {ab }}$ Jiaying Yan, ${ }^{\text {ab Nuonuo Zhang, }}$, \\ Kaibo Zheng ${ }^{\text {ab }}$ and Xiang Liu (D) *ab
}

\begin{abstract}
Herein, we report an in situ synthesis of graphene quantum dots (GQDs), which have been synthesized from only starch and water and stabilize AuNPs in water. The construction of six gold nanocomposites, i.e. AuNPs 1-6, with sizes ranging from $13.4 \mathrm{~nm}$ to $32.6 \mathrm{~nm}$, was accomplished by only mixing the GQDs and chloroauric acid in different amounts without any additional reductants and surfactants. HRTEM has confirmed that the AuNPs have been stabilized by the GQDs, and a core/shell AuNPsaGQD structure has formed. In addition, the as-synthesized AuNPs show excellent catalytic performance in the reduction of 4-nitrophenol, a pertinacious pollutant occurring in industrial wastewater.
\end{abstract}

Received 12th April 2019

Accepted 26th June 2019

DOI: 10.1039/c9ra02758k

rsc.li/rsc-advances and metallic impurities. Therefore, it is still a challenge to develop an eco-friendly alternative method for the synthesis of GQDs. In 2018, a green and efficient one-pot hydrothermal synthesis of GQDs, with a narrow size distribution range from 2.25 to $3.50 \mathrm{~nm}$, from only natural polymer starch and water was first reported by our group. In the synthetic process, at first, starch was mainly hydrolyzed to glucose, and it was subsequently converted into GQDs by cyclic condensation. Finally, the obtained GQDs were characterized by SEM, TEM, AFM, XPS, XRD, FTIR spectroscopy and Raman spectroscopy. ${ }^{10}$ Our group has a long-term interest in the synthesis of transition metal nanoparticles and their applications. ${ }^{11}$ Hence, in this study, we first report a green and facile method for the in situ synthesis of graphene quantum dot-stabilized AuNPs and their applications, where the GQDs have been obtained from only starch and water. ${ }^{10}$ The construction of the AuNPs 1-6 was accomplished by only mixing the GQDs and $\mathrm{HAuCl}_{4} \cdot 3 \mathrm{H}_{2} \mathrm{O}$ in different amounts without any additional reductants and surfactants. Then, their efficiency as catalysts in the degradation of 4nitrophenol upon reduction in water by sodium borohydride has been investigated by the kinetic studies including the determination of induction times and rate constants.

\section{Results and discussion}

\subsection{Synthesis of the AuNPs}

At first, the GQDs were synthesized from only commercial natural polymer starch and water using our previously reported method (Fig. 1). ${ }^{7}$ The obtained GQDs were well dispersed in water with a pale yellow color in sunlight, whereas the color would change to green under a $365 \mathrm{~nm}$ ultraviolet lamp (Fig. 2). This is owing to the characteristic unsaturated carbon-carbon double bond in GQDs. Transmission electron microscopy (TEM) also confirmed that the main diameter of the obtained 


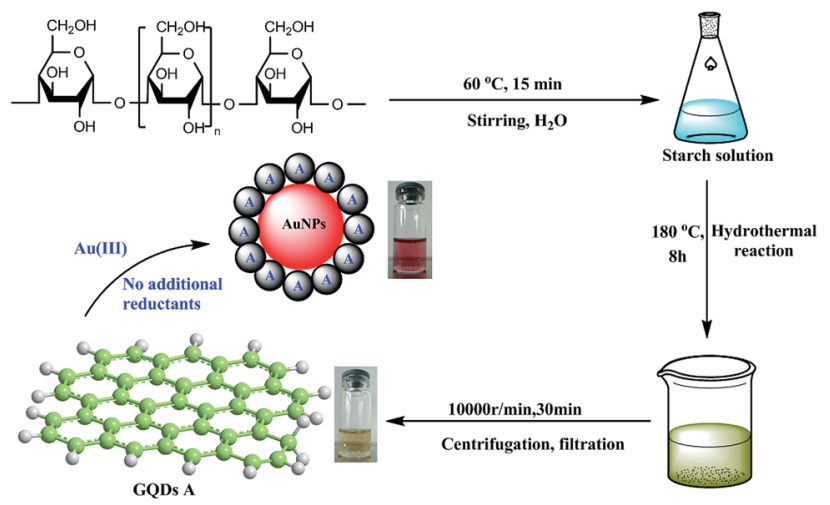

Fig. 1 The green synthesis of the AuNPs.

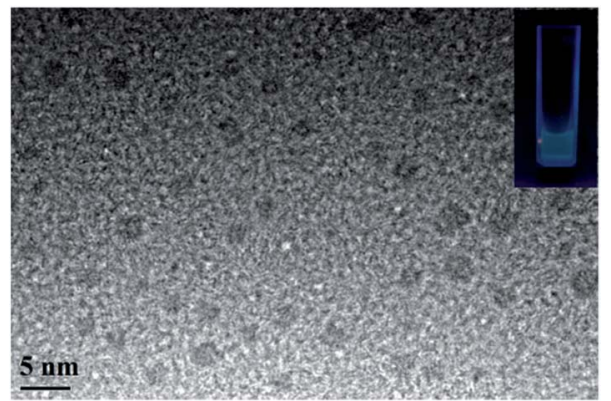

Fig. 2 A TEM image of the GQDs and an image of the GQDs under a UV-vis lamp (inset).

GQDs ranged from 2.25 to $3.50 \mathrm{~nm}$; then, $\mathrm{HAuCl}_{4} \cdot 3 \mathrm{H}_{2} \mathrm{O}$ in different amounts $\left(2.5 \times 10^{-4} \mathrm{mmol}, 0.625 \times 10^{-3} \mathrm{mmol}, 1.25\right.$ $\times 10^{-3} \mathrm{mmol}, 2.5 \times 10^{-3} \mathrm{mmol}$ and $5.0 \times 10^{-3} \mathrm{mmol}$ ) was added dropwise to the GQD solution at the same concentration at $0{ }^{\circ} \mathrm{C}$, provoking an immediate formation of the claret (AuNP) color (Fig. 1), corresponding to the reduction of the cation to the zero-valent metal and the formation of the AuNPs 1-5. The AuNP-6 was synthesized at $30{ }^{\circ} \mathrm{C}$ using the same amount of $\mathrm{HAuCl}_{4} \cdot 3 \mathrm{H}_{2} \mathrm{O}$ as used for AuNP-5. Furthermore, as a comparative experiment, the commercial natural polymer starch (instead of the GQDs) was tested under the same abovementioned condition. The result shows that the commercial natural polymer starch is insoluble in water at $0{ }^{\circ} \mathrm{C}$ or $30^{\circ} \mathrm{C}$ and does not reduce gold(III) salts to AuNPs.

Indeed, the GQDs are also successful reductants for the reduction of gold(III) salts to AuNPs because the AuNPs 1-6 show a surface plasmon band (SPB) at approximately $530 \mathrm{~nm}$, the characteristic peak of gold nanoparticles, in the observed UV-vis spectra (Table 1 and Fig. S1-S6 in ESI†). These AuNPs have been successfully stabilized via a net effect by the GQDs and the organic starch residue. Moreover, TEM was used to confirm the morphology and the size of the AuNPs. However, note that the reducing capacity of our GQDs is remarkably similar to that of ferrocene. ${ }^{\mathbf{1 2}}$ Thus, the reduction of chloroauric acid was slightly slower with the GQDs than that with the classic reducing agent sodium borohydride; this led to the formation of much larger AuNPs than those in the latter case as the sizes of the obtained AuNPs 1-5 were in the range between 13.4 and
$32.6 \mathrm{~nm}$ with different amounts of chloroauric acid (Fig. 3a-e). This size range is specifically optimal and useful for the application of AuNPs in cell imaging and biomedical usage. ${ }^{13}$ Moreover, the size of these AuNPs was modulated by varying the reaction temperature. The AuNP-6 $(30.0 \mathrm{~nm})$ obtained at $30{ }^{\circ} \mathrm{C}$ was much larger than the AuNP-5 obtained at $0{ }^{\circ} \mathrm{C}(13.4 \mathrm{~nm})$. This is probably due to Ostwald ripening that occurs at $30{ }^{\circ} \mathrm{C}$ following the $\mathrm{Au}$ atom nucleation, which in turn causes a decrease in the number of Au nuclei and the AuNP overgrowth. ${ }^{14}$ Moreover, the representative high-resolution transmission electron microscopy (HRTEM) image of AuNP-5 exhibits the $\mathrm{Au}$ (111), (311), (220) and (200) lattice fringe distances of $0.231 \mathrm{~nm}, 0.122 \mathrm{~nm}, 0.148 \mathrm{~nm}$ and $0.202 \mathrm{~nm}$ in the inner region, respectively. However, the lattice spaces (020) and (002) of the graphitic carbon are $0.250 \mathrm{~nm}$ and $0.357 \mathrm{~nm}$, respectively, on the surface of the nanoparticles (Fig. S7 in ESI $\dagger$ ); it is obvious that the inner region of the AuNPs has been stabilized by the GQDs, and as a result, a core/shell AuNPs@GQD structure is formed. More importantly, in the FTIR spectrum of the AuNPs-5 (Fig. S8 $\dagger$ ), the peaks at 1631 and $1402 \mathrm{~cm}^{-1}$ are related to the skeletal vibrations of the aromatic rings of the GQDs, whereas the weak peaks at 1053 and $2923 \mathrm{~cm}^{-1}$ are the stretching vibrations of the $\mathrm{C}-\mathrm{O}$ and $\mathrm{C}-\mathrm{H}$ bond in the aromatic rings, respectively, confirming the honeycomb lattice of the graphene structure in the AuNP-5. Moreover, the UV-vis absorption peak intensity of the AuNPs versus reaction time for the AuNPs 1-6 was investigated. The result shows that the UV-vis absorption peak intensity of the AuNPs no longer increases after approximately 40 hours, indicating that the reductant (GQDs) has been used up (Fig. S9-S20 in ESI $\dagger$ ). Furthermore, the crystalline nature of the AuNP-5 was determined using X-ray diffraction (XRD), where five $\mathrm{Au}$ diffraction peaks, i.e. Au (111), (200), (220), (311) and (222), as well as that of graphene (002) were observed in the $2 \theta$ range of $10-80^{\circ}$, which matched with the JCPDS card no. 75-0444 and 040784 (Fig. 4). To further verify the formation of the AuNPs, the Xray photoelectron spectroscopy (XPS) spectra of AuNP 1 and 5 were obtained. The XPS spectra of 1 show the Au $4 \mathrm{f}$ peak positions at 84.0 and $87.6 \mathrm{eV}$. The binding energies of $84.0 \mathrm{eV}$ and $87.6 \mathrm{eV}$ for $\mathrm{Au} 4 \mathrm{f}_{7 / 2}$ and $4 \mathrm{f}_{5 / 2}$, respectively, are exclusively assigned to the zero-valent surface atoms of the AuNPs (Fig. 5a). In other words, the $\mathrm{Au}^{3+}$ ions were probably bonded and reduced by the $-\mathrm{COOH}$ and $-\mathrm{OH}$ groups of the GQDs, and further, the as-obtained AuNPs were stabilized by these- $\mathrm{COOH}$ and $-\mathrm{OH}$ groups. Au $4 \mathrm{f}$ was fitted with two pair of peaks for the $\mathrm{Au} 4 \mathrm{f}_{5 / 2}$ and $4 \mathrm{f}_{7 / 2}$ doublets in the XPS spectra of AuNP-5. The Au $4 \mathrm{f}_{7 / 2}$ peak positions were around 84.3 and $87.0 \mathrm{eV}$. These positions at $84.3 \mathrm{eV}$ and $87.0 \mathrm{eV}$ were assigned to $\mathrm{Au}(0)$ and $\mathrm{Au}(\mathrm{III})$, respectively (Fig. 5b). Obviously, chloroauric acid was not completely reduced by the GQDs under these reaction conditions as the amount of $\mathrm{HAuCl}_{4}$ gradually increased. ${ }^{15}$

\subsection{Compared catalytic activities of 1-6 in the 4-nitrophenol reduction by $\mathrm{NaBH}_{4}$}

4-Nitrophenol is the accessory substance of the procedures used for manufacturing pigments, pesticides, and pharmaceuticals 
Table 1 4-Nitrophenol reduction catalyzed by AuNPs in water ${ }^{a}$

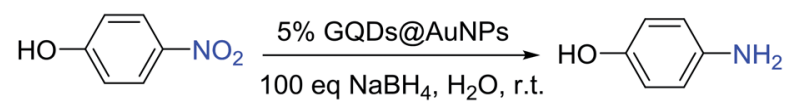

\begin{tabular}{lcllll}
\hline Entry & $\mathrm{HAuCl}_{4}(\mathrm{mmol})$ & AuNPs & $T_{0}{ }^{c}(\mathrm{~s})$ & $k_{\mathrm{app}}{ }^{d} \times 10^{-3} \mathrm{~s}^{-1}$ & $\mathrm{SPB}^{e}(\mathrm{~nm})$ \\
\hline 1 & $2.5 \times 10^{-4}$ & 1 & 540 & 1.9 & 527 \\
2 & $0.625 \times 10^{-3}$ & 2 & 0 & 3.9 & 530 \\
3 & $1.25 \times 10^{-3}$ & 3 & 0 & 5.8 & 533 \\
4 & $2.5 \times 10^{-3}$ & 4 & 0 & 6.4 & 531 \\
5 & $5.0 \times 10^{-3}$ & 5 & 0 & 9.3 & 538 \\
$6^{b}$ & $5.0 \times 10^{-3}$ & 6 & 0 & 9.2 & 533
\end{tabular}

${ }^{a} 5.0 \mathrm{~mol} \%$ AuNPs were used for catalyzing 4-nitrophenol reduction with $\mathrm{NaBH}_{4}$ being in excess (100/1). All the AuNPs $1-5$ were synthesized at $0{ }^{\circ} \mathrm{C}$ except $6 .{ }^{b}$ The AuNP-6 was synthesized at $30{ }^{\circ} \mathrm{C}^{c}{ }^{c}$ Induction time. ${ }^{d}$ Rate constant. ${ }^{e}$ Surface plasmon band. ${ }^{f}$ Core size (from SEM or TEM) of the AuNPs.

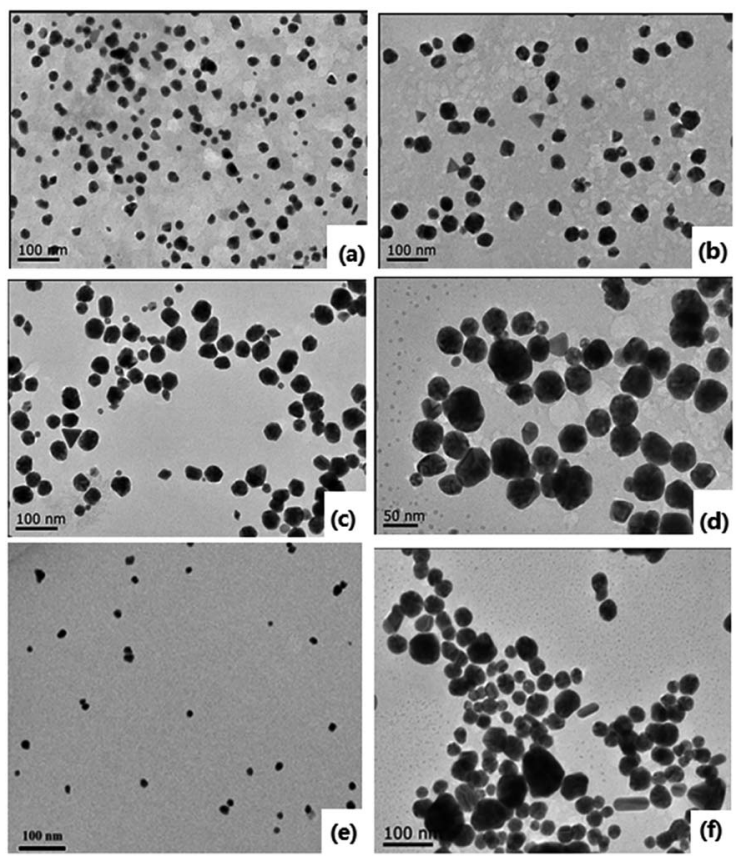

Fig. 3 TEM images of the AuNPs. (a)-(f) 1-6.

in industry and hence regarded as one of the most highly poisonous and hazardous pollutants. The reduction of 4-nitrophenol to 4 -aminophenol is extensively catalyzed by metal nanoparticles, and this reduction is well-known to be very sensitive to the nature of the metal nanoparticle surface. ${ }^{16}$ Moreover, it is very convenient to monitor the progress of the reduction of 4-nitrophenol to 4-aminophenol by UV-vis spectroscopic analysis due to their typical absorption peaks at $\lambda=$ $400 \mathrm{~nm}$ (4-nitrophenol) and $300 \mathrm{~nm}$ (4-aminophenol). ${ }^{160}$ Therefore, to evaluate the catalysis capability of the synthesized AuNPs 1-6 as nanocatalysts, they were examined through the reduction of 4-nitrophenol (Table 1). The degradation of 4nitrophenol has been carried out in the presence of $5.0 \mathrm{~mol} \%$ AuNPs with 100 equiv of sodium borohydride in water at room temperature, and this large excess of sodium borohydride has been usually used in the literature to induce an apparent firstorder kinetics and a relative lack of competitive sodium borohydride hydrolysis by water as a solvent. According to the experimental results, the reduction reaction did not need induction time in the presence of $5 \mathrm{~mol} \%$ AuNPs except for the case of the AuNP-1 (Table 1, entries 1-6).

Only the catalysis by the AuNP-1 was found to be slow and required the induction time of $540 \mathrm{~s}$ due to the reorganization of the catalyst surface; this issue of induction time requirement was rectified by the stabilization of the AuNP-1 with excess GQDs that generated a partial steric inhibition for the substrate to access the surface of the AuNPs (Fig. 4a). Thus, the AuNP-1 was used in $5 \% \mathrm{mmol}$ only, providing $k_{\text {app }}=1.9 \times 10^{-3}$ (Table 1, entry 1). The reaction rate $k_{\text {app }}$ of the corresponding AuNPs increases in the order of $1<2<3<4<5$ simultaneously as the amount of chloroauric acid increases during the process of the synthesis (Fig. S21-S32 in ESI†). According to this rule, we also tried to synthesize AuNPs with high amount of chloroauric acid. Unfortunately, the AuNPs produced were unstable and immediately aggregated due to this concentration increase. Interestingly, the AuNP-6 showed the same reaction rate as

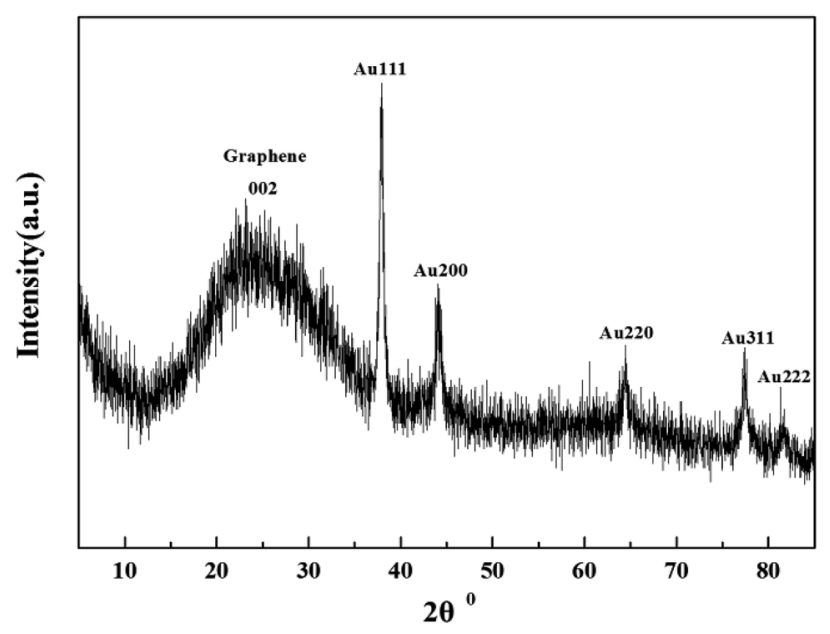

Fig. 4 XRD spectra of AuNPs-5. 

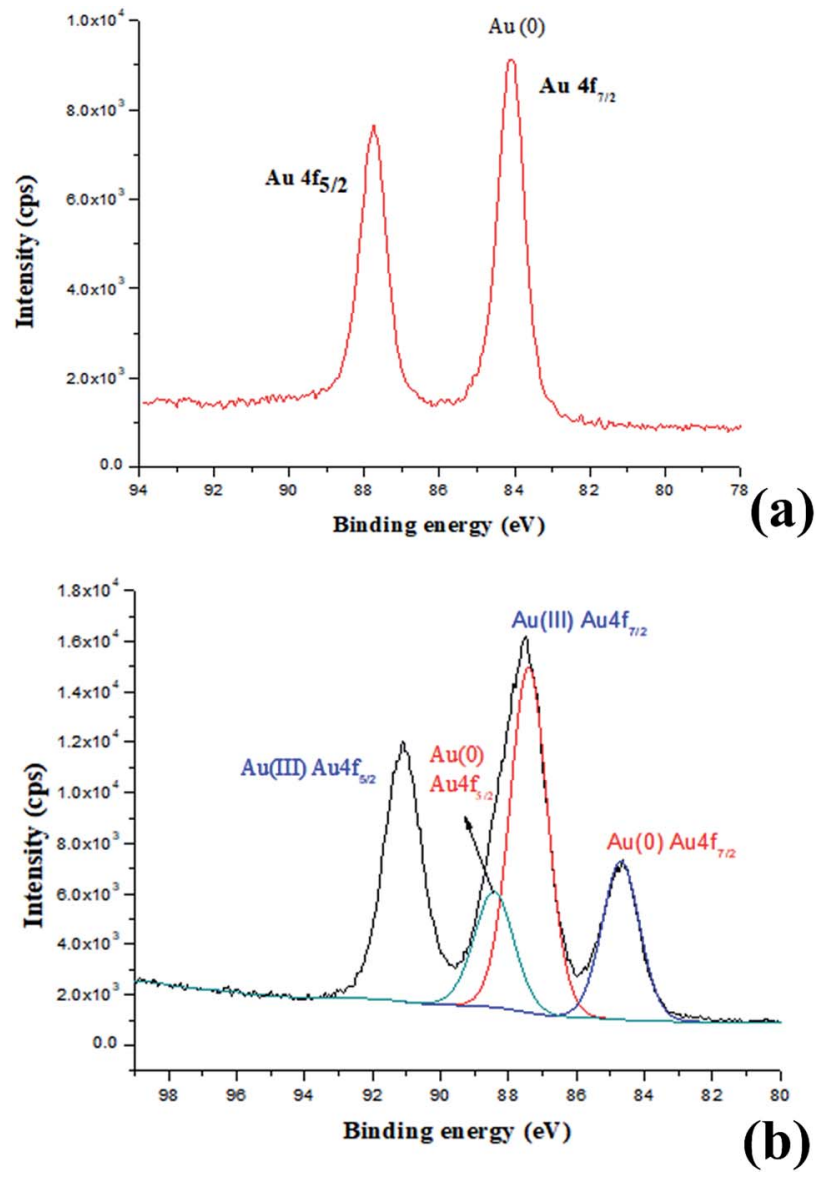

Fig. 5 (a) XPS spectra of AuNPs-1 and (b) XPS spectra of AuNPs-5.

AuNP-5, i.e. $k_{\text {app }}=9.2 \times 10^{-3}$, although the size of $6(30.0 \mathrm{~nm})$ was almost two times that of $5(13.4 \mathrm{~nm})$. It is clear that the AuNP-5 shows the highest reaction rate among all the synthesized AuNPs (Table 1, entry 5), and this is consistent with the smallest size of $13.4 \mathrm{~nm}$ of the AuNP-5. Moreover, the GQDs alone do not catalyze the degradation of 4-nitrophenol under these conditions (Fig. S33 in ESI†). In addition, an overall mechanistic model of this reaction is shown and has been discussed in Fig. S34 in ESI. $\dagger$

\section{Conclusion}

Herein, a green and facile method for the in situ synthesis of graphene quantum dot (GQD)-stabilized $\mathrm{Au}$ nanoparticles (AuNPs) in water was developed. It first involves the successful synthesis of GQD from only starch and water. The construction of the AuNPs 1-6 nanocomposites was accomplished by only mixing the GQDs and chloroauric acid in different amounts without any additional reductants and surfactants. The TEM images show that the sizes of the AuNPs 1-6 are between 13.4 and $32.6 \mathrm{~nm}$. This size range is specifically optimal and useful for the application of AuNPs in cell imaging and biomedical usage. Furthermore, the HRTEM showed that the AuNPs (inner) were stabilized by GQDs, and consequently, a core/shell AuNPs@GQDs structure had emerged. The reducing driving force of these GQDs is much weaker than that of other strong reducing agents such as $\mathrm{NaBH}_{4}$, whereas it is remarkably similar to that of ferrocene. Both the GQDs and ferrocene reduce $\mathrm{Au}$ (III) with a modest driving force, which results in the formation of much larger AuNPs than those obtained using the strong reductant $\mathrm{NaBH}_{4}$. Furthermore, the catalytic efficiency of these different nanocomposites in the degradation of 4-nitrophenol by sodium borohydride in water was demonstrated, and these composites were compared by investigating their 4nitrophenol reduction kinetics via the determination of induction times and rate constants. In conclusion, these GQD@AuNP nanocomposites show wide potential applications in the cell imaging, sensing, and catalysis fields.

\section{Conflicts of interest}

There are no conflicts to declare.

\section{Acknowledgements}

Financial support received from the National Natural Science Foundation of China (Grant No. 21805166 and 21606145), Natural Science Foundation of Hubei Province (Grant No. 2018CFB386), the 111 Project of Hubei Province (Grant No. 2018-19-1), State Key Laboratory of Coordination Chemistry Foundation of Nanjing University (No. SKLCC1811) and China Three Gorges University is gratefully acknowledged.

\section{Notes and references}

1 (a) M.-C. Daniel and D. Astruc, Chem. Rev., 2004, 104, 293346; (b) G. Yue, S. Su, N. Li, M. Shuai, X. Lai, D. Astruc and P. Zhao, Coord. Chem. Rev., 2016, 311, 75-84; (c) C. Gautier and T. Burgi, ChemphysChem, 2009, 10, 483-492; (d) J. Zheng, C. Zhou, M. Yu and J. Liu, Nanoscale, 2012, 4, 4073-4083; (e) P. Ghosh, G. Han, M. De, C. Kyu, K. Vincent and M. Rotello, Adv. Drug Delivery Rev., 2008, 60, 13071315; (f) R. A. Sperling, P. R. Gil, F. Zhang, M. Zanellaa and W. J. Parak, Chem. Soc. Rev., 2008, 37, 1896-1908; $(g)$ R. Sardar, A. M. Funston, P. Mulvaney and R. W. Murray, Langmuir, 2009, 25, 13840-13851; (h) D. A. Giljohann, D. S. Seferos, W. L. Daniel, M. D. Massich, P. C. Patel and C. A. Mirkin, Angew. Chem., Int. Ed., 2010, 49, 3280-3294; (i) W. Zhou, X. Gao, D. Liu and X. Chen, Chem. Rev., 2015, 115, 10575-10636; (j) X.-Q. Qiao, Z.-W. Zhang, F.-Y. Tian, D.-F. Hou, Z.-F. Tian, D.-S. Li and Q.-C. Zhang, Cryst. Growth Des., 2017, 17, 3538-3547; (k) J. J. Du, C. Chen, Y. L. Gan, R. H. Zhang, C.-Y. Yang and X. W. Zhou, Energy, 2014, 39, 17634-17637; (l) Z. Kang, X. Tan, X. Li, T. Xiao, L. Zhang and J. Lao, Phys. Chem. Chem. Phys., 2016, 18, 1992-1997.

2 H. Kang, J. T. Buchman, R. S. Rodriguez, H. L. Ring, J. He, K. C. Bantz and C. L. Haynes, Chem. Rev., 2019, 119, 664-699.

3 (a) P. Zhao, N. Li and D. Astruc, Coord. Chem. Rev., 2013, 257, 638-665; (b) N. Li, P. Zhao and D. Astruc, Angew. Chem., Int. Ed., 2014, 53, 1756-1789. 
4 (a) X. M. Li, M. C. Rui and J. Z. Song, Adv. Funct. Mater., 2015, 25, 4929-4947; (b) M. Bacon, S. J. Bradley and T. Nann, Part. Part. Syst. Charact., 2014, 31, 415-428; (c) L. S. Li and X. Yan, J. Phys. Chem. Lett., 2010, 1, 2572-2576; (d) H. Tetsuka, R. Asahi, A. Nagoya, K. Okamoto, I. Tajima, R. Ohta and A. Okamoto, Adv. Mater., 2012, 24, 5333-5338; (e) N. Suzuki, Y. Wang, P. Elvati, Z.-B. Qu, K. Kim, S. Jiang, E. Baumeister, J. Lee, B. Yeom, J. H. Bahng, J. Lee, A. Violi and N. A. Kotov, ACS Nano, 2016, 10, 1744-1755; (f) J. Peng, W. Gao, B. K. Gupta, Z. Liu, R. R. Aburto, L. Ge, L. Song, L. B. Alemany, X. Zhan, G. Gao, S. A. Vithayathil, B. A. Kaipparettu, A. A. Marti, T. Hayashi, J.-J. Zhu and P. M. Ajayan, Nano Lett., 2012, 12, 844-849; (g) C. X. Guo, H. B. Yang, Z. M. Sheng, Z. S. Lu, Q. L. Song and C. M. Li, Angew. Chem., Int. Ed., 2010, 49, 3014-3017; (h) L. A. Ponomarenko, F. Schedin, M. I. Katsnelson, R. Yang, E. W. Hill, K. S. Novoselov and A. K. Geim, Science, 2008, 320, 356-358; (i) F. Liu, M.-H. Jang, H. D. Ha, J.-H. Kim, Y.-H. Cho and T. S. Seo, Adv. Mater., 2013, 25, 3657-3662.

5 (a) W. S. Kuo, H. H. Chen, S. Y. Chen, C. Y. Chang, P. C. Chen, Y. I. Hou, Y. T. Shao, H. F. Kao, C. L. Lilian Hsu, Y. C. Chen, S. J. Chen, S. R. Wu and J. Y. Wang, Biomaterials, 2017, 120, 185-194; (b) W. Chen, J. Shen, G. Lv, D. Li, Y. Hu, C. Zhou, X. Liu and Z. Dai, ChemistrySelect, 2019, 4, 2898-2902.

6 K. A. Ritter and J. W. Lyding, Nat. Mater., 2009, 8, 235-242.

7 (a) X. Niu, Y. Zhong, R. Chen, F. Wang, Y. Liu and D. Luo, Sens. Actuators, B, 2018, 255, 1577-1581; (b) Q. Lu, W. Wei, Z. Zhou, Z. Zhou, Y. Zhang and S. Liu, Analyst, 2014, 139, 2404-2410; (c) W. Lv, Y. Ju, Y. Chen and X. Chen, Int. J. Hydrogen Energy, 2018, 43, 10334-10340; (d) Y. Zhua, S. Lu, A. G. Manoharia, X. Dong, F. Chen, W. Xu, Z. Shi and C. Xu, J. Electroanal. Chem., 2017, 796, 75-81.

8 (a) X. Zhou, Y. Zhang, C. Wang, X. Wu, Y. Yang, B. Zheng, H. Wu, S. Guo and J. Zhang, ACS Nano, 2012, 6, 6592-6599; (b) J. P. Melo, P. L. Ríos, P. Povea, C. Morales-Verdejo and M. B. Camarada, ACS Omega, 2018, 3, 7278-7287.

9 W. Chen, G. Lv, W. Hu, D. Li, S. Chen and Z. Dai, Nanotechnol. Rev., 2018, 7, 157-185.
10 W. Chen, D. Li, L. Tian, W. Xiang, T. Wang, W. Hu, Y. Hu, S. Chen, J. Chen and Z. Dai, Green Chem., 2018, 20, 44384442 .

11 (a) X. Liu and D. Astruc, Coord. Chem. Rev., 2018, 359, 112126; (b) X. Liu and D. Astruc, Adv. Mater., 2017, 29, 1605305; (c) X. Liu, J. Ruiz and D. Astruc, Chem. Commun., 2017, 53, 11134-11137; (d) X. Liu and D. Astruc, Adv. Synth. Catal., 2018, 360, 3426-3459; (e) X. Liu and J.-R. Hamon, Coord. Chem. Rev., 2019, 389, 94-118; (f) X. Liu, D. Gregurec, J. Irigoyen, A. Martinez, S. Moya, R. Ciganda, P. Hermange, J. Ruiz and D. Astruc, Nat. Commun., 2016, 7, 13152; (g) X. Liu, J. Ruiz and D. Astruc, J. Inorg. Organomet. Polym., 2018, 28, 399-406; (h) D. Astruc, C. Deraedt, R. Djeda, C. Ornelas, X. Liu, A. Rapakousiou, J. Ruiz, Y. Wang and Q. Wang, Molecules, 2018, 23, 966; (i) X. Liu, Y. Huang, X. Meng, J. Li, D. Wang, Y. Chen, D. Tang and B. Chen, Synlett, 2019, 30, 1026-1036; (j) J. Yan, G. Liu, N. Li, N. Zhang and X. Liu, Eur. J. Inorg. Chem., 2019, 2806-2810.

12 (a) R. Ciganda, J. Irigoyen, D. Gregurec, R. Hernandez, S. Moya, C. Wang, J. Ruiz and D. Astruc, Inorg. Chem., 2016, 55, 6361-6363; (b) R. Ciganda, H. Gu, R. Hernández, A. Escobar, A. Martínez, L. Yate, S. Moya, J. Ruiz and D. Astruc, Inorg. Chem., 2017, 56, 2784-2791; (c) D. Astruc, Eur. J. Inorg. Chem., 2017, 6-29.

13 K. Saha, S. S. Agasti, C. Kim, X. N. Li and V. M. Rotello, Chem. Rev., 2012, 112, 2739-2779.

14 Y. Bia and G. Lu, Chem. Commun., 2008, 6402-6404.

15 M. Yamashita, H. Ohashi, Y. Kobayashi, Y. Okaue, T. Kurisaki, H. Wakita and T. Yokoyama, J. Colloid Interface Sci., 2008, 319, 25-29.

16 (a) A. A. Pal and T. Pal, Chem. Commun., 2015, 51, 9410-9431; (b) P. Hervés, M. Pérez-Lorenzo, L. M. Liz-Marzàn, J. Dzubiella, Y. Lu and M. Ballauff, Chem. Soc. Rev., 2012, 41, 5577-5587; (c) P. Zhao, X. Feng, D. Huang, G. Yang and D. Astruc, Coord. Chem. Rev., 2015, 287, 114-136; (d) C. Deraedt, L. Salmon, S. Gatard, R. Ciganda, R. Hernandez, J. Ruiz and D. Astruc, Chem. Commun., 2014, 50, 14194-14196. 